\title{
Towards a methodology for values-based architecture
}

\author{
A. E. Williams \\ soft loud house architects, Australia
}

\begin{abstract}
Values-based architecture is the conscious interweaving of the story of what it is that people value into the creation of the places and spaces they dwell in and the things that they use. Inherent in the understanding of values-based architecture is the awareness that the things we create guide our actions, thoughts and emotions. This is very different from 'modernist' thinking which failed to value the nature of relationships and connections between people, culture and place, as well as the rich and diverse biological cycle of the earth.

soft loud house architects have been developing and refining a process for values-based architecture for over fifteen years. That process began with building an awareness of ourselves and of the practice's values - to know who we were and why we were doing what we were doing. A vocabulary needed to be established for the effective communication of these values. The next step was to listen carefully to our clients, to develop an understanding of their values and needs, and to bring these into the creative process through language, text, drawing, image, and action. The outcomes of this approach were periodically recorded through post-occupancy evaluation.

This paper aims to formalise our understanding of this developing methodology of values-based architecture, and to assess its potential contribution to the creation of sustainable architecture.

Keywords: architectural design, design methodology, values-based design, human needs, ontological design, sustainable architecture, values, values-based architecture.
\end{abstract}

\section{Introduction}

This paper represents a point in time in a process of discovery. Unlike more typical academic studies, it is based almost entirely on praxis, an interweaving and 
evolving relationship between an unmeasurable number of theoretical positions and practical responses.

Values-based architecture has been developed over the last fifteen years as the foundation of our architectural practice at soft loud house architects in Australia. From interactions with the wider academic and professional world, I am aware that this design process is neither commonplace nor well understood. Valuesbased architecture is premised on the understanding that everything in life and in practice ultimately concerns relationships.

In City Futures in the Age of a Changing Climate, Fry [1] asserts that we live in a global condition of 'unsettlement', defined as a crisis of meaning and direction. This has led humanity into structural unsustainability, where the future is sacrificed in service of the present. Crompton [2], WWF-UK's change strategist, in Common Cause: The Case For Working With Our Cultural Values, suggests that if the actions required of us upon becoming aware of our unsustainability conflict with our values, any information we receive bounces off, or remains outside us. In this way, educating or informing people of how they might live more sustainably has little effect on their actions from the point at which their values are challenged.

When we encounter knowledge that challenges our point of view, many of us avoid, contest, deny, debate, or run away from it. Values-based architecture is an approach or methodology that seeks to engage people in a conversation that both reflects upon and challenges their actions in relation to their basic personal values. This paper sets out to explore this methodology outside the context of our architectural practice.

\section{Values-based architecture}

Values-based architecture is an architectural design process. It is based on a conscious awareness of who we are, how we understand the world, and what we value, and applied to addressing our needs and goals in relation to creating sustainable shelter.

In this design process a framework of personal or community values is developed, guiding our design responses so that they reflect those values. While the physical result of values-based architecture is typically a building (the one the client has commissioned us to design), sometimes the most appropriate response isn't a building, for the design process may uncover a need for something else.

This raises the question of whether values-based architecture can make a significant contribution to a more sustainable practice of providing shelter. Through engaging our clients in a conversation about what it is that they value, they develop a vocabulary for values, learning how to prioritise and distinguish a 'framework of values' to support their decisions as proposed by Lakoff and Johnston [3] in Metaphors We Live By. In relation to civil society organisations, Crompton [4] suggests that a conversation about values, guides people towards prioritising the values they already hold, to align with being more sustainable. Our observations in working with clients in our architectural practice confirms this. Once clients have a vocabulary and have prioritised their values, they begin to 
align themselves with 'self-transcendent' or more community-orientated values. They tend to move away from self-interested and extrinsic values (how they would like to be seen by others) and towards more intrinsic values (how they want to see or know themselves).

In a recent project, a client noted that her values were so misaligned to her needs that she couldn't sleep. The project was put on hold to allow her time to adapt to this new understanding of her values, and bring some coherence to her values, goals and actions.

\section{Values}

Our practice's working understanding of 'values' in the context of values-based architecture, is defined as the things that humans care about, think about, and consume. If I were to describe an elegant suburban house with a spacious garage and three highly polished vintage sports cars parked outside, you might feel justified in thinking that the owners of this house value quality real estate, expensive toys, pleasure, beauty, tradition, and order. Or you might think that they prize other values such as freedom or status.

The values that come to the forefront in values-based architecture, more often than not, relate to the non-physical, the philosophical or the spiritual. They are values that we all cultivate to make sense of our world, and our place within it.

Schwartz [5], in his Universals in the Content and Structure of Values, argues that as human beings what we value is guided or informed by where we come from, our specific environment, culture, family, and even more exclusively, our personal and social experiences. What makes one person's values different from another's is that each of us has lived different experiences and been exposed to different cultural and existential influences.

To look at this from another angle, it may be useful to consider briefly how it is that humans construct their idea or understanding of the world. According to Lakoff and Johnston [6], humans understand their environment and experience the world around them through the use of metaphor, which is pervasive in our speech and writing. Valuing one metaphor over another can have profound implications for us culturally and personally. The 'time is money' metaphor is an example used widely to guide our thoughts and actions in our personal and business relationships. This metaphor collapses our assumptions about time and money. Within this metaphor, the direction of time becomes linear, and the quantity of time as a resource becomes limited. Like money, time becomes something that must be preserved. In contrast, Pallasmaa [7] proposes that time can be seen in many different ways: slow time, thick time, aesthetic time, etc. For example, he describes aesthetic time as time that is slowed down enough by the presence of beauty to allow our perceptions and memory to mingle. Pallasmaa suggests that what time is, and the way we experience it, may not be something that can be universally agreed upon. 


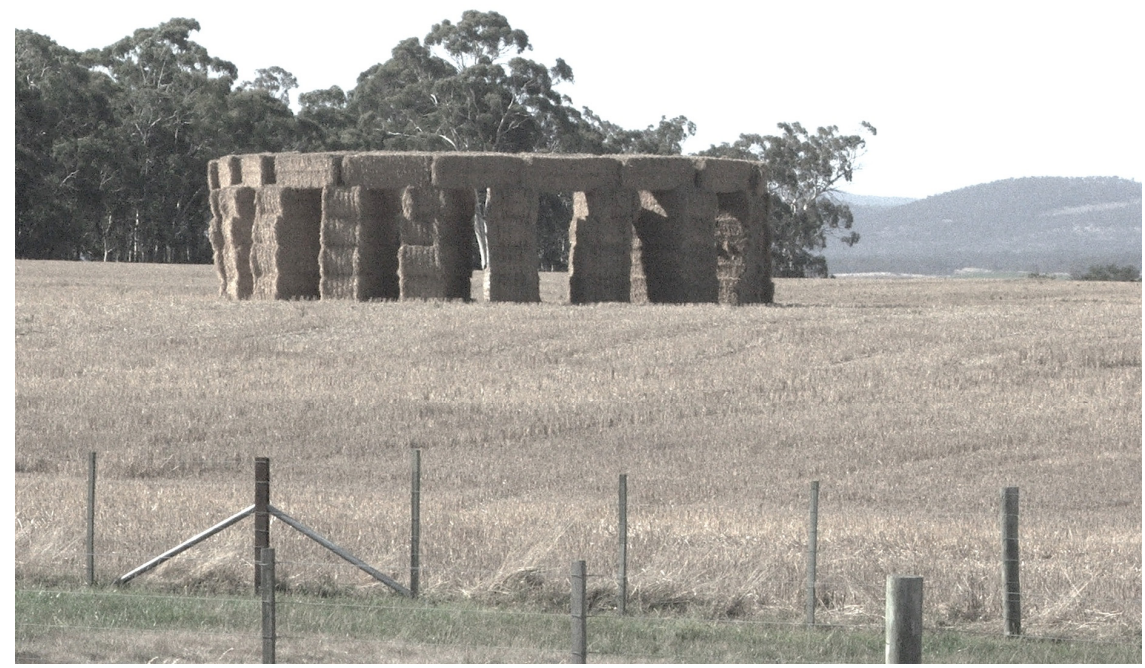

Figure 1: What are the values that "Strawhenge" communicates? Northern Tasmania 2006 (A. Williams).

Humans frequently make assumptions and rarely re-examine the way we have constructed our understanding of the world. In prioritising metaphors of linearity, contemporary Western culture differs from other cultures that have prioritised the idea of cyclic balance or flow. The structurally unsustainable urban environment we have brought into existence frighteningly reflects this thinking.

\section{Ontological design}

Winston Churchill famously said that "we shape our buildings, thereafter they shape us". Anne-Marie Willis [8] defines ontological design as the awareness that the built or modified environment "acts back on us". What we humans design goes on to design us in an interpretive feedback loop.

Eighty-five per cent of Australians live in cities. The built environment that has been designed and constructed for them has become an almost exclusive container for their lives, creating a profound and increasing dislocation between themselves, those around them, and the natural world. The experiences they have in this environment arise not only from their relationship with the physical built elements, and their interaction with natural forces, but also from their exposure to media, literature, theatre, music, and the arts, and so much more.

A built environment demonstrating this idea is 'The Sad Hill Cemetery', created as a set for Sergio Leone's film The Good, the Bad and the Ugly. This fictional cemetery has become an icon and reference for contemporary cemetery design, with its image indistinguishable from what is or was real. 


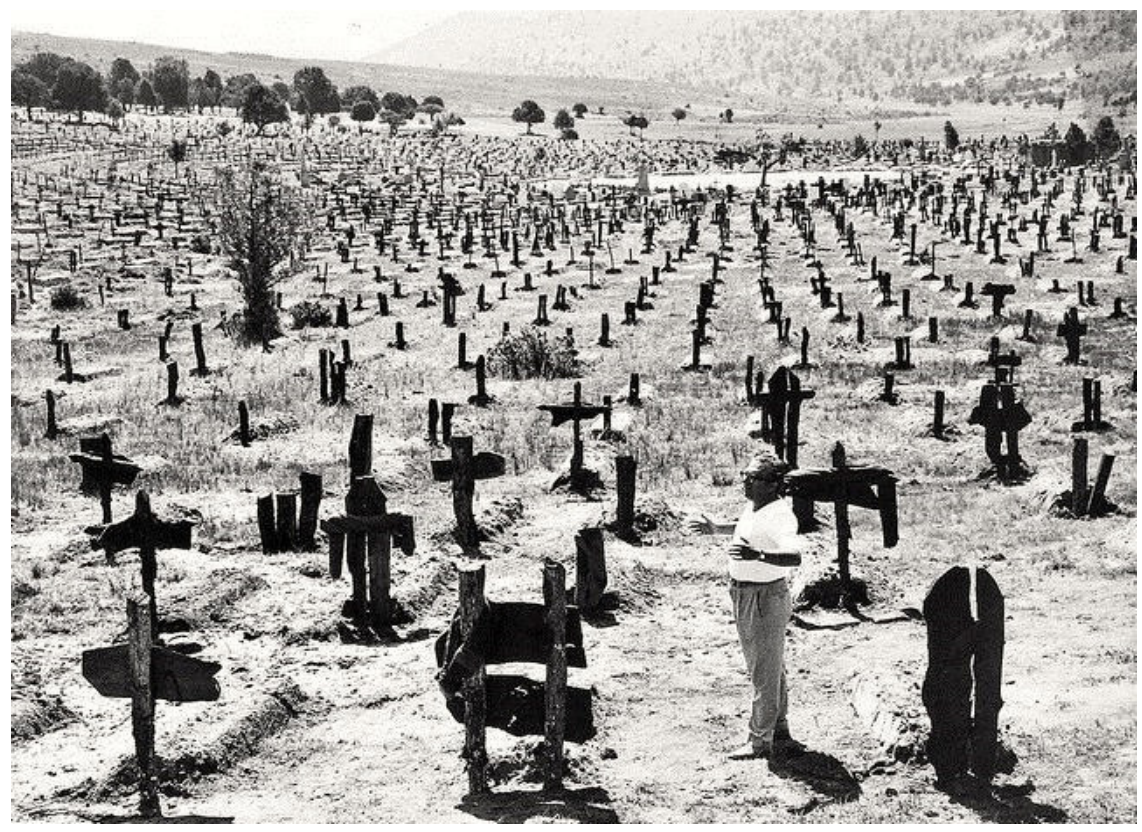

Figure 2: $\quad$ Sad Hill Cemetery, 'The Good, The Bad and the Ugly' Sergio Leone 1966 (production designer, Carlo Simi).

From the perspective of ontological design, the tendency of our media towards negativity, violence, doom and its particular focus on inhumane or dehumanised behaviour, influences the thoughts and actions of the people of the future.

\section{Being subjective}

As the founder of soft loud house architects, the natural and built environment in which I was raised, educated, and trained was the source of the experiences, filters and prejudices through which I see and understand the world. Following on from the idea that our environment designs us, it becomes difficult to describe the use of a methodology of values-based architecture without first introducing who I am and where I came from. It is similarly difficult to distil which experiences and memories have contributed to shaping my values and thus that of the practice.

I was born in England in the early 1970s in a family with one foot standing either side of a class divide. Both my parents valued education and desired to live connected to the rhythms of nature. They wanted to farm and build their own home. Politically and socially, England was not an easy place in the 1970s for them to thrive, and by the time I was seven, we had relocated to Australia. I grew up amongst animals, crops and wilderness, and as part of a rural community.

As a teenager holidaying in France, my grandfather introduced me to the worn stones of Roman architecture, and the notion that everything we do as humans leaves marks on the earth. Even after two millennia, you could still know 
something of what those Romans cared about. I developed an interest in the stories that architecture could tell in relation to human values.

At university, the subjectivity that we impressionable students brought into the academic world was whittled away by the requirement to become objective. From my exposure to political activism, psychology, art and design, I became keenly aware of the tension between the social mission of architecture and a rising push towards aestheticisation - directly related to the disconnection of architecture from environmental concerns. Most importantly, I questioned the boundaries of the field of architecture that had been presented as the status quo.

I found employment with the architect Greg Burgess, an enigmatic figure in Australian architecture in the 1990s, spending the best part of a decade undertaking a close apprenticeship in organic architecture - a listening architecture that responded to indigenous culture, and the human spirit. In observing how Greg practiced, I became aware of the way his listening, thinking, and understanding produced a different material outcome to the work of most other architects. This working environment strongly informed the values underlying my architectural practice today.

\section{Being in practice}

I formed soft loud house architects in 1999. Rather than expressing the creative exhortations of my own ego, I wanted to be of service to clients, supporting them to realise their own projects. I began with a manifesto about the sort of architect I wanted to be, the sort of practical and environment-orientated organisation I wished to create, and the beginnings of an attempt to identify a guiding philosophy for a practice worth working with. To do this, I had to let go of a lot of things, and learn more about the needs, goals and values of my clients.

The office slowly grew, and I became we. Not just as staff, but there were always children, family, craftspeople, neighbours and friends, all with colourful opinions and personalities. It was a creative multicultural practice, regularly using an interdisciplinary approach.

We questioned our clients, developing rich and detailed project briefs as a default, expressing their needs and goals in language before attempting a design response. In hindsight, we were beginning a conversation about values. While every project brief was unique, what evolved universally was a discussion concerning two key questions, "what is being at home for you?" and "what do you want to know about yourself?" We gleaned more information to guide our design responses from these questions than any other part of the brief, realising that a project was more successful when this information was shared amongst the whole team, including builders and labourers. These values became embodied in the realisation of the project. We measured the 'success' of the process by how effectively a client's values and needs had been met. The client's values had become the assessment tools used in decision making throughout the project, and this decision-making could and did continue beyond our involvement.

In 2010, we undertook the design for an Underground House in Steels Creek (figure 3), in response to the original house having been destroyed by bushfire. 
This was also the family home that I had grown up in. The project brief needed to address increasing bushfire risks and climate change, and embodied the values of resilience, practicality, humility, environmental protection, self-sufficiency and beauty.

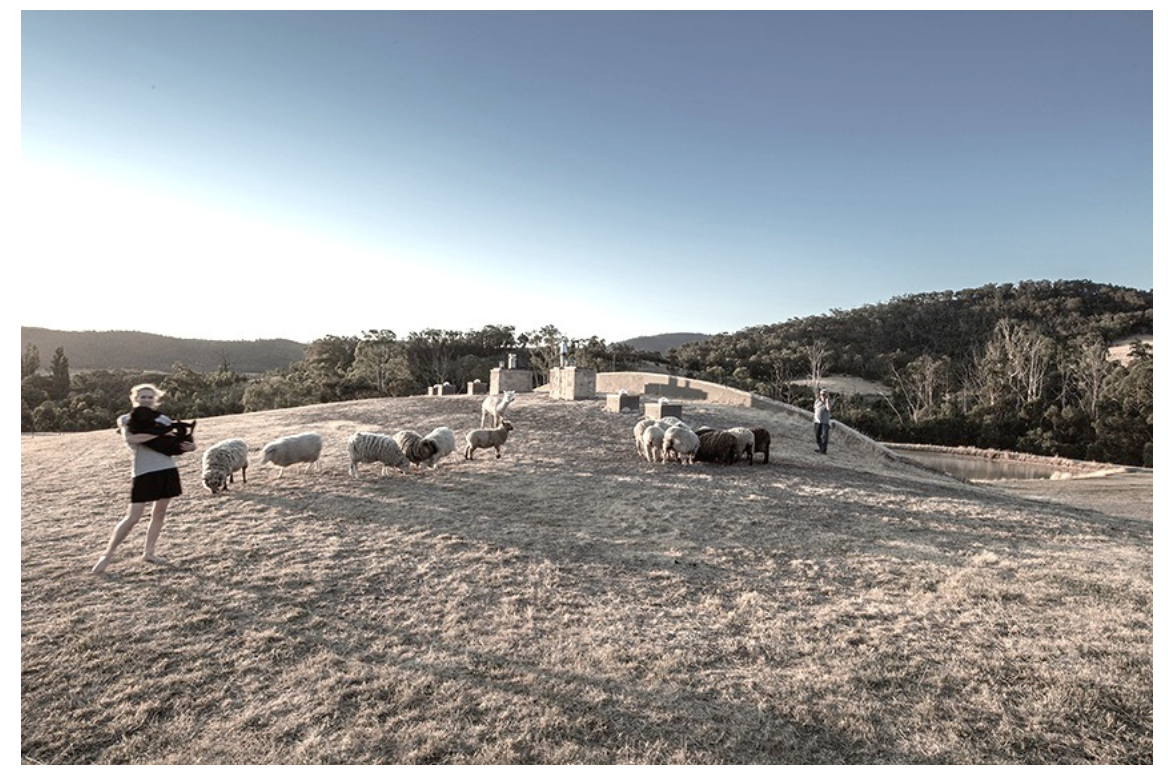

Figure 3: Underground House, Steels Creek, soft loud house architects 2016 (Image: Ben Wrigley).

We refined our methodology through post-occupancy evaluation, creating an assessment tool to measure how well the client's values had been captured in relation to the design, construction process and building performance overall. We found that most clients preferred an independent party to ask these questions, and consequently, the use of an online questionnaire was developed.

\section{Reflection}

It was not until 2013 that I first attempted to communicate our methodology as an entire process. By that time, soft loud house architects had grown and shrunk, and had been refined, burned, raised from the ashes, and refined yet again. We were invited to present our work in Perth, Western Australia.

In my research and preparation for this presentation, I came across the term values-based design, not in relation to architecture, but to hospital fitout. I realised that we had been using this approach all along, and how different it was to the way that most architects worked. With a new vocabulary with which to communicate, it was time to begin some deeper research into what people cared about, the 
relationship between shelter, values and being, and more importantly, what was happening in that field elsewhere.

\section{Is there a developing field of values-based architecture?}

Surprisingly, 'values-based architecture' is a term rarely used in relation to architecture itself, though it is becoming used outside a context of constructing the built environment, alluding to the role of the architect in design and the implementation of design. Patel [9] mentions 'values-based institutions' and 'values-based engagement' between the U.S. and Asia in the context of diplomatic engagement. Green and Twining [10] use the terms 'values based architecture', 'values-based diplomacy', 'values-based cooperation' and 'values-based strategy' in a similar context. Similarly, the consideration of human values, and use of the term 'values-based' in relation to socially-orientated gaming and software design is discussed by Flanagan et al. [11]. Crompton references Schwartz's [12] extensive work on the content and structure of human values. The social values underlying technology design (for example valuing privacy) are considered by Koepfler et al. [13], in regard to online social relationships. Shilton [14] in Value Levers: Building Ethics into Design goes on to discuss the development of a relationship between designers, ethics and social values, and the use of 'values levers' to promote the prioritisation of social values as an essential part of design processes. Coming closer to a relationship between values and architecture (Steward and Kuska [15]) discussed the need for a 'values-based design' in the context of conserving natural resources by reusing building materials and considering design for reassembly.

The term 'architecture' is used frequently in this context as a metaphor for the coordination and construction of something of such complexity, that skills, experience and training must be employed in order to bring it to fruition. In relation to values-based architectural design, this field can be seen as a clearing - an open and unconstrained place for new seeds to be sown. I am describing a place that has been prepared for the making of a sustainable culture, deliberately using the metaphors and language of agriculture. Building too is another way of making culture.

\section{Conclusion}

In a number of fields, there is an emerging 'values-based' methodology where the term is used to prefix not only architecture and design, but also diplomacy, relationships and decision-making. A wider conversation about a need for valuesbased architecture is also evolving, specifically in relation to human-created environments, which are physical, conceptual and spiritual in dimension. These environments, and the way we see and understand them significantly shape our individual experiences, thoughts and actions.

Where this conversation about values appears to be leading, is towards an ability to transcend self-interest and develop a way to understand, communicate and work respectfully across different cultures and environments. In developing a 
consciousness around values, the conditions that create them, and understanding why some are prioritised over others, we can each acknowledge our different cultures and experiences, and support the creation of an interconnected and holistic understanding of what it is to be human.

The wider this relationship-based conversation becomes, the greater our ability will be to develop culturally sustainable and appropriate responses to our rapidly changing environment.

\section{References}

[1] Fry, T. City Futures in the Age of a Changing Climate, Routledge, 2014.

[2] Crompton, T. Common Cause: the case for working with our cultural values, WWF-UK, 2010.

[3] Lakoff, G. \& Johnston, M. Metaphors We Live By, University of Chicago Press, 2008.

[4] Crompton, T. Common Cause: the case for working with our cultural values, WWF-UK, 2010.

[5] Schwartz, S.H. "Universals in the content and structure of values: Theoretical advances and empirical tests in 20 countries." Advances in experimental social psychology 25.1 (pp. 1-65) 1992.

[6] Lakoff, G. \& Johnston, M. Metaphors we live by, University of Chicago Press, 2008.

[7] Pallasmaa, J. "Dwelling in Time: The Architectural Meaning of Time" lecture Melbourne, March 2016.

[8] Willis, A.-M. "Ontological Designing." Design philosophy papers 4.2, (pp. 69-92) 2006.

[9] Patel, N. "The Strategic Environment of US-Sino Relations." China's Arrival: A Strategic Framework for a Global Relationship (pp. 3-18) 2009.

[10] Green, M. \& Twining, D. "Power and Norms in U.S. Asia Strategy: Constructing an Ideational Architecture to Encourage China's Peaceful Rise", China's Arrival, (pp. 111-136) 2009.

[11] Flanagan, M. Howe D.C. \& Nissenbaum H. "Values at play: Design tradeoffs in socially-oriented game design." Proceedings of the SIGCHI conference on human factors in computing systems, ACM 2005.

[12] Schwartz, S.H. "Universals in the content and structure of values: Theoretical advances and empirical tests in 20 countries." Advances in experimental social psychology 25.1 (pp. 1-65) 1992.

[13] Koepfler, J.A. Shilton, K. \& Fleischmann, K.R. "A stake in the issue of homelessness: Identifying values of interest for design in online communities", Proceedings of the 6th International Conference on Communities and Technologies, ACM 2013.

[14] Shilton, K. "Values levers: Building ethics into design." Science, Technology \& Human Values (p. 12) 2012.

[15] Steward W.C. \& Kuska, S "Structuring research for 'Design for Deconstruction'." Deconstruction and Building Material Reuse Conference, 2004. 